\title{
VALUE PROPOSITION OF PRODUCT-SERVICE SYSTEMS: AN EXPERIMENTAL STUDY TO COMPARE TWO DIFFERENT DESIGN APPROACHES
}

\author{
S. C. Fernandes ${ }^{1,2, \otimes}$, D. C. A. Pigosso ${ }^{2}$, T. C. McAloone ${ }^{2}$ and H. Rozenfeld ${ }^{1}$ \\ ${ }^{1}$ University of São Paulo, Brazil, ${ }^{2}$ DTU-Technical University of Denmark, Denmark \\ $\triangle$ saniafernandes@usp.br
}

\begin{abstract}
The development of product-service systems (PSS) requires the design of value propositions, which involves challenging activities. In the context of business model innovation, gamification is presented as a practical mechanism to support the design process. This study aims to create a prototype of a gamified approach to design PSS value propositions and to compare its application to a traditional design approach. Based on a design experiment, the advantages and problems for both approaches were evaluated, providing insights for further development of the new version of the gamified approach.
\end{abstract}

Keywords: product-service systems (PSS), business models, early design phase, design tools

\section{Introduction}

Product-service system (PSS) is an alternative for companies to innovate and generate additional value in markets, where improving products is no longer enough. This innovation encompasses an integrated offering of products and services (Boehm and Thomas, 2013). Servitization is the transition process, from traditional business model to one that offers PSS (Baines et al., 2017).

Developing a PSS implies an innovation of the business model (Rozenfeld et al., 2018), by altering how the resources and capabilities are converted into solutions. A central dimension that guides the business model design is the value proposition (Laurischkat and Viertelhausen, 2017). PSS value propositions denote the value that the company may offer to customers and other stakeholders, through products and services (Resta et al., 2017). The design of value propositions influences the creation and improvement of offerings and the reconfiguration of systems (Maglio and Spohrer, 2013).

Based on a review of literature, the process to design PSS value propositions can be said to encompass five main innovation steps, which should be carried out iteratively:

- Understanding: this step encompasses activities related to the understanding of the current situation of the company through internal and external analysis and understanding of customers and other stakeholders (Pezzotta et al., 2016; Baldassarre et al., 2017; Hein et al., 2018).

- Ideation: this step primarily focuses on generating ideas and consolidating PSS value propositions to solve the needs, problems, and opportunities of customers and other stakeholders (Geissdoerfer et al., 2016; Fernandes et al., 2018).

- Selection: includes activities to select PSS value propositions based on different criteria or aspects (Fernandes et al., 2018). 
- Evaluation: includes the evaluation/assessment of value propositions with respect to the consequences of each solution (Baldassarre et al., 2017; Rau et al., 2017).

- Experimentation: addresses the development of prototypes to test/experiment the value proposition with customers and other stakeholders (Leitão et al., 2013; Geissdoerfer et al., 2016; Baldassarre et al., 2017).

Although some approaches have been proposed to design PSS, only few methods and tools have been developed to support the design of PSS value propositions. Only recently, studies have investigated how to create or improve value propositions (Åkesson et al., 2016; Pogue et al., 2016). There is still a need for a practical and systematic mechanism to support the design of value propositions for PSS business models, such as frameworks, gamified approaches, or visualization tools.

In business activities, gamification is presented as an opportunity to support the design process (Duin and Hauge, 2008). Gamification refers to the transfer of game design elements to non-game environments. It aids "in having visibility in the early phase of design" (Kerga et al., 2014, p. 343), while providing a common source for the exploitation of business model innovation. It is considered as a powerful toolkit to apply in a business context by encompassing two aspects, the understanding of the game design process and business techniques (Werbach and Hunter, 2012).

Inspired by a previous study that developed a game-based methodology for e-mobility business model innovation (Laurischkat and Viertelhausen, 2017), the hypothesis developed for this study is that in the perception of participants, a gamified approach is more effective in the design of PSS value propositions in comparison to a traditional design approach when fostering motivation and performance, facilitating discussions, and providing better experience satisfaction. In the context of this study, effectiveness is related to the understanding and usability of approaches, how they contribute to consolidating the value propositions, and how they promote motivation (i.e. how they energize and give meaning to behaviour and actions), discussion and a satisfactory experience to participants in applying the approaches (relative to their emotional reaction). The effectiveness was measured based on participants' perceptions.

To test the hypothesis, this study aims to develop a prototype of a gamified approach to support the design of PSS value propositions and to compare its application to a traditional design approach (which does not employ gamification) through an experiment.

This paper presents a gamified approach to design PSS value propositions, the differences regarding the traditional approach, the experiment configured to apply both approaches, and the results related to the process of application. The analysis of the quality of the value propositions is not considered in the scope of this study since the focus is on the design process itself rather than on the outcomes of it. The main contribution of this study is the systematization of a process to design PSS value propositions, the assessment of whether a gamified approach can facilitate this design (encompassing its elements, steps and general characteristics) in relation to a traditional approach, and the unique aspects that should be considered when applying a gamified approach.

This paper is structured as follows. Section 2 describes the research methodology. Section 3 describes the gamified approach developed in this research. Results from the experiment when comparing the gamified approach with a traditional design approach are described in section 4 , and section 5 presents the main findings and lessons learned. The paper ends with section 6 , which presents the conclusion.

\section{Research methodology}

This study followed the game design process (Werbach and Hunter, 2012; Martin, 2017) to develop the prototype of a gamified approach that aims to support the design of PSS value propositions (sub-section 2.1). Through a design experiment, an empirical interventional study was conducted to analyse the applicability of the gamified approach compared to a traditional design approach (sub-section 2.2).

\subsection{Game design process}

The development of the prototype of the gamified approach followed a qualitative and iterative process consisting of five steps (Figure 1): concept definition, pre-prototyping, prototyping, tests, and improvements (Werbach and Hunter, 2012; Martin, 2017). 


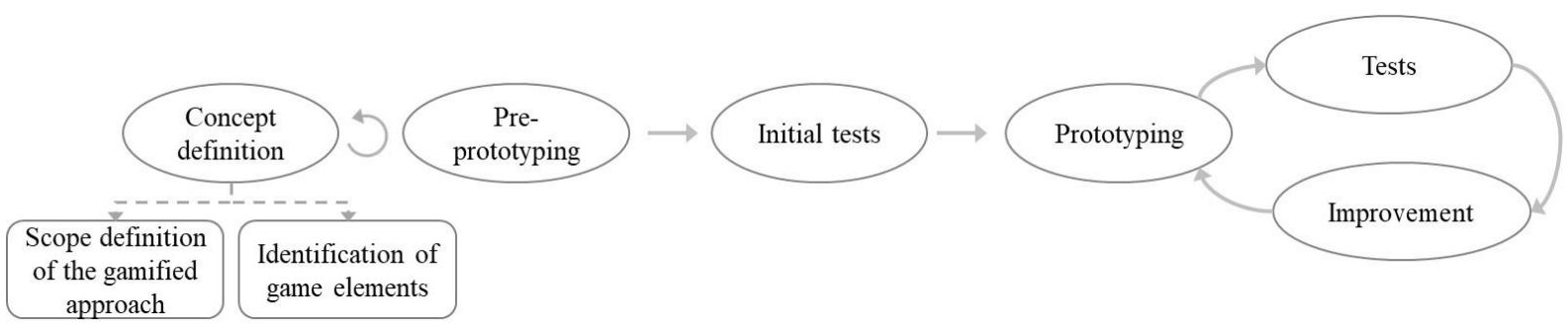

Figure 1. Game design process to develop the prototype of the gamified approach (adapted from Werbach and Hunter (2012); Martin (2017))

In the first activity of concept definition, the scope of the gamified approach with respect to the innovation steps for designing PSS value propositions was defined. Three conditions were delineated to decide which innovation steps should be covered by the gamified approach. The conditions are:

1. the steps should depend on input information already consolidated prior to application, i.e. do not require activities to be performed outside the gaming environment;

2. the steps can be applied sequentially and immediately according to their output-input ratio;

3. the steps can be applied in a timely manner considering the time constraints in companies to apply the gamified approach.

Based on those conditions, the scope of the gamified approach was defined to provide gameful experiences for practitioners when generating ideas, creating and selecting PSS value propositions. Only the steps of ideation and selection were addressed in the gamified approach, as the others (understanding, evaluation, and experimentation) demand information and/or decisions that could go beyond the setting of a gamified approach (considering the progression throughout a gamified approach and the involvement of players).

The second activity of concept definition was the identification of game elements that should be considered and managed when developing the gamified approach. Game elements are features or characteristics relevant to gamification, comprising dynamics, mechanisms, and components (Werbach and Hunter, 2012; Schell, 2015). The elements were defined considering the nature of each innovation step covered by the gamified approach. Since the game design process is iterative, the employment of the game elements was balanced and adjusted during gameful experiences by analysing the particularities in relationships between the mechanisms and components employed.

An initial version of the prototype of the gamified approach was developed in the step of pre-prototyping to gain empathy and learning about gamification, creating conditions to bring out new information regarding the concept definition of the approach. The overall process described by Fernandes et al. (2018) was used as a basis to develop the pre-prototype. This process was selected since it was exclusively developed to design value propositions in the context of a servitization and PSS design methodology (Rozenfeld et al., 2018). A scenario to apply the pre-prototype was prepared, based on a previous PSS case study (Fernandes et al., 2018). Two initial tests were conducted with researchers in workshops that occurred within a period of six hours.

Based on insights and feedback obtained from participants when testing the pre-prototype, prototypes of the gamified approach were developed. In this step, knowledge from process models described in PSS literature (e.g., Geissdoerfer et al. (2016), Baldassarre et al. (2017) and Breuer and Lüdeke-Freund (2014)) enriched the development of the prototypes of the gamified approach. Three tests were planned and executed with researchers in workshops whose duration varied between three and four hours. First, the gamified approach was introduced to participants and then it was played. Feedback from players was obtained during and after application. To record and process information, the researcher employed audio recording, formal debriefing sessions before and after the prototypes' application, direct observation, informal conversations (Voss et al., 2002), and research diaries (Symon, 2004).

From developing one prototype to another, improvements opportunities for the gamified approach were identified based on the analysis of evidence collected from prototype testing. Improvement opportunities were mainly related to the rules and procedures of the gamified approach. After a few iterations, a new version of prototype was set to be applied in a design experiment and tested by users. The description of the gamified approach (compared to the traditional design approach) is provided in Section 3. 


\subsection{Design experiment}

An experiment was conducted to evaluate the prototype of the gamified approach, in comparison with a traditional design approach (see Section 3). The research hypothesis (Section 1) was tested by analysing the experiment adopting an observation approach and a feedback questionnaire. The experiment was conducted with 52 students from a PSS course of a design engineering Masters Programme. Different backgrounds and competencies of students simulated the conditions faced by cross-functional teams in companies. Masters students can be considered the target group when developing new design approaches since they are advanced beginners (Kleinsmann et al., 2012).

The students had been randomly divided into thirteen groups composed either of 3 to 5 individuals. Each group was working on a PSS case (defined by professors from the beginning of the PSS course) from different sectors and industries (fashion and textile, mobility/passenger transport services, assets management). Prior to the experiment, students had already consolidated the information related to the innovation step of understanding, which is the input to apply the steps covered by the gamified approach (ideation and selection). This information concerned the identification of current PSS value proposition, understanding of stakeholders, PSS life cycle, and environmental and cost impacts for each PSS case. The challenge had a PSS design orientation, with the business scenario considering the improvement of the PSS value proposition to address the current issues identified in each PSS business model.

The experiment lasted 2.5 hours. It featured a 15-minute introduction with an explanation about the value proposition construct in PSS domain and a brief explanation of the purpose of the activity at hand. It was followed by a two-hour design session, where the groups were asked to follow instructions (Section 3), representing the "knowledge baseline", to define a new value proposition for the PSS cases. Six groups (considering a total of 22 students) received instructional information on the basis of a gamified approach, and seven groups (in a total of 30 students) received information that guided the creation of a new PSS value proposition on the basis of a traditional approach. It is important to highlight that all groups followed the same steps (what to do), to ensure comparability between approaches. However, as described in Section 3, the approaches differed in terms of the elements employed to each one and on how to combine different content to design a new PSS value proposition. In the end, a 15minute session was deployed, to get feedback from students through discussions. The students were also asked to complete a feedback questionnaire.

During the experiment, the students' behaviour was observed, with respect to activity involvement and group discussions. Questions asked by students about how to apply the approaches were recorded through the use of research diaries (Symon, 2004) and further processed.

The feedback questionnaire was developed based on the method proposed by Echeveste et al. (2007) for structuring research protocols. The questionnaire comprised a combination of multiple-choice (first section) and open-ended questions (second section). The first section contained seven questions with answers distributed on the Likert scale, varying from 1 (completely disagree) to 5 (completely agree). Multiple-choice questions were related to seven aspects: (i) understanding of approach; (ii) usability of approach; (iii) common understanding of the PSS value proposition; (iv) consolidation of a new PSS value proposition; (v) discussions encouragement; (vi) group's motivation; (vii) satisfaction with the new PSS value proposition. The second section contained three questions that required an open answer to evaluate the approaches in three aspects: (i) greatest advantages; (ii) greatest difficulties when applying the approach; (iii) open feedback from the respondents.

To evaluate the degree of agreement among respondents on the questions answered with the Likert scale, the interrater reliability (IRR) was calculated. This index shows the alignment and similarity degree among the answers. It can vary from 0 to 1 , where the maximum value stands for complete concordance. In this research, a minimum interrater reliability coefficient of 0.5 is required to consider that the respondents achieved a consensus (based on Fernandes et al. (2018)). We highlight that the evaluation of the degree of agreement was based on the responses of the total number of students rather than by groups (22 students for the gamified approach and 30 students for the traditional approach). The students answered the questionnaire individually in relation to the specific approach they had employed. They were just organized into groups as a way of delivering the approaches and conducting the experiment. 
For each question to be evaluated (designated $X_{j}$ ), the within-group interrater reliability (represented as $\left.r_{w g(1)}\right)$ is calculated by the following equation (Equation 1) (James et al., 1984).

$$
r_{w g(1)}=1-\left(\frac{s_{X_{J}}{ }^{2}}{\sigma_{E U^{2}}}\right)
$$

In that equation, $s_{x_{j}}{ }^{2}$ is the observed variance, and ${\sigma_{E U}}^{2}$ is the variance expected in case all judgments were due to random measurement error. The expected variance $\left(\sigma_{E U}{ }^{2}\right)$ is calculated with Equation (2) (James et al., 1984), where $A$ is the number of alternatives in the score scale (i.e., 5 alternatives).

$$
\sigma_{E U}^{2}=\frac{\left(A^{2}-1\right)}{12}
$$

In respect to the open-ended questions, the descriptive justifications provided by the respondents were synthesized to achieve further conclusions.

\section{Gamified approach to design PSS value propositions}

The gamified approach is being developed as a collaborative approach in which the players act together to achieve the goal of designing new PSS value propositions. This goal, adapted to the reality of each PSS case, provides meaning and purpose for players.

Both gamified and traditional approaches follow the same activities to ensure comparability between them, but differ on how the content is presented (regarding the instructions and components applied). The interaction components included in each approach are depicted in Figure 2.

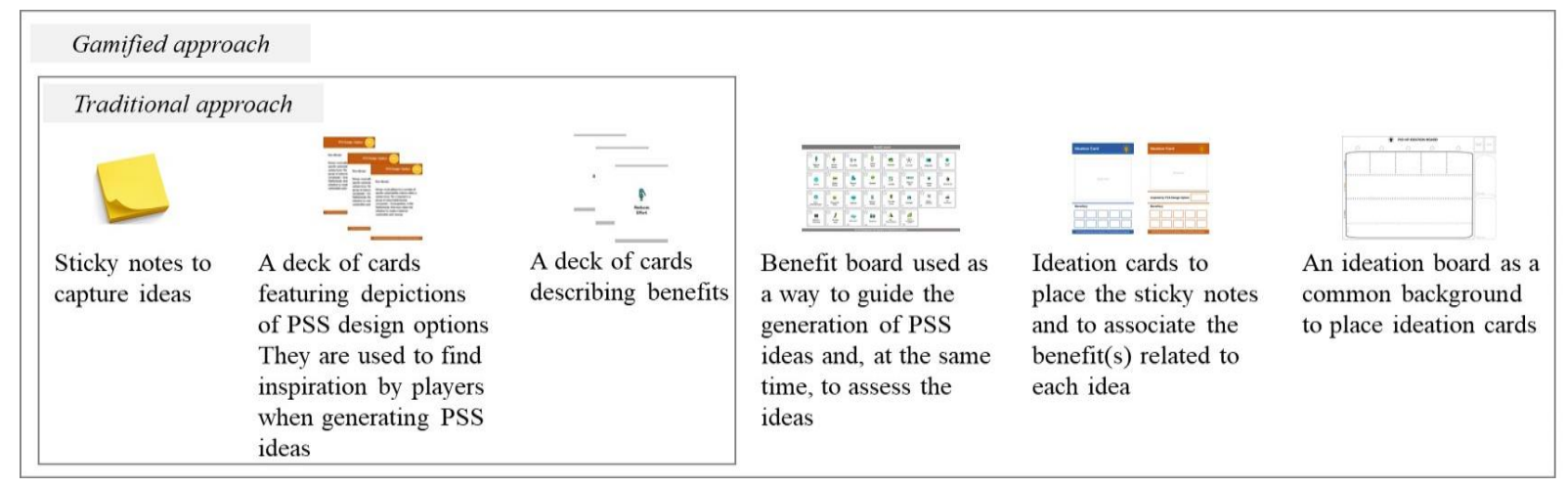

Figure 2. Components included in the gamified and traditional approaches (elaborated by authors)

The approaches consist of five activities that are built upon each other and have a different focus. Inputs to apply the approaches unfold from the analysis of the PSS cases referring to the needs, problems, and opportunities that customers and other stakeholders might be facing. Table 1 provides a description of the steps and the corresponding specificities for each approach.

Table 1. Description of steps for gamified and traditional approaches (elaborated by authors)

\begin{tabular}{|l|l|l|l|}
\hline $\begin{array}{c}\text { Innovation } \\
\text { step }\end{array}$ & \multicolumn{1}{|c|}{ Activities } & \multicolumn{1}{c|}{ Gamified approach } & \multicolumn{1}{c|}{ Traditional design approach } \\
\hline Ideation & $\begin{array}{l}\text { Scenario setting: } \\
\text { identification of the } \\
\text { relevant benefits the } \\
\text { PSS should generate }\end{array}$ & $\begin{array}{l}\text { Each player should state the } \\
\text { benefits in the benefit board each } \\
\text { one received }\end{array}$ & $\begin{array}{l}\text { Participants do not receive a } \\
\text { specific instruction on how to } \\
\text { point out the benefits }\end{array}$ \\
\cline { 2 - 4 } & $\begin{array}{l}\text { Brainstorming: } \\
\text { generation of ideas of } \\
\text { products and services } \\
\text { to promote the } \\
\text { benefits. It was } \\
\text { proposed for freeing } \\
\text { the mind of students }\end{array}$ & $\begin{array}{l}\text { Individually brainstorming. After } \\
\text { the individual ideation session, } \\
\text { players present their ideas while } \\
\text { placing the ideation cards on the } \\
\text { correspondent layer on the ideation } \\
\text { board. Players receive victory } \\
\text { points for each idea generated }\end{array}$ & $\begin{array}{l}\text { Participants can decide on } \\
\text { individual or group brainstorming }\end{array}$ \\
\hline
\end{tabular}




\begin{tabular}{|c|c|c|c|}
\hline $\begin{array}{l}\text { Innovation } \\
\text { step }\end{array}$ & Activities & Gamified approach & Traditional design approach \\
\hline \multirow[t]{2}{*}{ Ideation } & $\begin{array}{l}\text { Stimulating ideas } \\
\text { generation: } \\
\text { generation of } \\
\text { additional ideas by } \\
\text { using PSS design } \\
\text { options cards }\end{array}$ & $\begin{array}{l}\text { Each player advances up to three } \\
\text { ideas with the highest number of } \\
\text { benefits. In groups of two/three } \\
\text { individuals, players pick up PSS } \\
\text { design options cards, dealt } \\
\text { randomly, to come up with } \\
\text { additional ideas that complement } \\
\text { the selected ideas from previous } \\
\text { activity. Groups of players present } \\
\text { their ideas while placing the } \\
\text { ideation cards on the correspondent } \\
\text { layer on the ideation board. Groups } \\
\text { of ideas are scored by the number } \\
\text { of benefits related to them. }\end{array}$ & $\begin{array}{l}\text { Participants receive PSS design } \\
\text { options cards to come up with } \\
\text { additional ideas. Participants do } \\
\text { not receive a specific instruction } \\
\text { on how to organize the ideas } \\
\text { generated. }\end{array}$ \\
\hline & $\begin{array}{l}\text { Combination of } \\
\text { ideas: } \\
\text { Bringing together } \\
\text { complementary ideas }\end{array}$ & $\begin{array}{l}\text { Players should advance up to five } \\
\text { groups of ideas with the highest } \\
\text { number of benefits. Based on the } \\
\text { analysis of groups of ideas, players } \\
\text { should combine them into different } \\
\text { value propositions. Adverse effects } \\
\text { (sacrifices to customers and other } \\
\text { stakeholders) the value proposition } \\
\text { may generate should be discussed } \\
\text { and write down in sticky notes. }\end{array}$ & $\begin{array}{l}\text { Based on the analysis of ideas, } \\
\text { which may be organized } \\
\text { unstructured (depending on } \\
\text { previous activity), participants } \\
\text { should combine them into } \\
\text { different value propositions. } \\
\text { Adverse effects (sacrifices to } \\
\text { customers and other stakeholders) } \\
\text { the value proposition may } \\
\text { generate should be discussed and } \\
\text { write down in sticky notes. }\end{array}$ \\
\hline Selection & $\begin{array}{l}\text { Selection: } \\
\text { choosing a value } \\
\text { proposition }\end{array}$ & \multicolumn{2}{|c|}{$\begin{array}{l}\text { A value proposition is selected based on the analysis of the impact of } \\
\text { the benefits versus sacrifices. A statement should be written. }\end{array}$} \\
\hline
\end{tabular}

Table 2 presents the general characteristics for both gamified and traditional approaches.

Table 2. General characteristics for the gamified and traditional approaches (elaborated by authors)

\begin{tabular}{|c|c|}
\hline $\begin{array}{l}\text { Gamified } \\
\text { approach }\end{array}$ & $\begin{array}{l}\text { - Played over three rounds, which include one or more activities: } \\
\text { Round } 1 \text { (scenario setting and brainstorming) } \\
\text { Round } 2 \text { (stimulating ideas generation) } \\
\text { Round } 3 \text { (combination of ideas and selection) } \\
\text { - Gaming rules are described in cards and define the meaning, function, and relations between } \\
\text { components. At the same time, rules define the scope of possible actions for players. } \\
\text { - Participants assume a fantasy-role of the basic profiles in the context of value proposition } \\
\text { design. The roles are related to marketing \& sales department, portfolio (product/service) } \\
\text { department, new business department, sustainability department, and customer. They are } \\
\text { assigned to provide a perspective to players when transferring the know-how into the process. } \\
\text { - Victory points are given to players in the first round, and a score is associated to ideas in the } \\
\text { second round (no more for each player, demonstrating the collaborative design). }\end{array}$ \\
\hline $\begin{array}{l}\text { Traditional } \\
\text { approach }\end{array}$ & $\begin{array}{l}\text { - A step-by-step approach (the approach is not divided into rounds). } \\
\text { - Instructions are also described in cards, but differ on details on how to proceed in each step, } \\
\text { suggesting self-management by the participants. }\end{array}$ \\
\hline
\end{tabular}

\section{Results from the experiment}

Participants were actively involved in applying the approaches. Collaboration among students into the same group was observed to both understand the applicability of approaches and to perform the proposed activities at hand. No difference was observed among groups working with the gamified 
approach and the traditional design approach. In general, participants of all groups were engaged throughout the experiment, sharing their knowledge in a participatory manner.

For both approaches, questions arose regarding the number of benefits to be selected in the first step (scenario setting); the nature of sacrifices (whether they were negative impacts on the business or just aspects that avoided achieving the benefits); and what to do with ideas that have not been consolidated into a value proposition. Such questions might indicate that the participants were really involved in the activity at hand and in understanding the content of approaches rather than applying them mechanically.

The answers to the questionnaire were statistically analysed according to the interrater reliability coefficient. A total of 22 students answered the questionnaire with respect to the gamified approach, and 30 students in relation to the traditional approach. The final values are presented in Table 3.

Table 3. Results from the experiment based on the feedback questionnaire (elaborated by authors)

\begin{tabular}{|c|c|c|c|c|}
\hline & \multicolumn{2}{|c|}{$\begin{array}{c}\text { Gamified approach } \\
(\mathrm{k}=22 \text { respondents })\end{array}$} & \multicolumn{2}{|c|}{$\begin{array}{l}\text { Traditional approach } \\
(\mathrm{k}=30 \text { respondents })\end{array}$} \\
\hline & $\bar{X}$ & $r_{w g(1)}$ & $\bar{X}$ & $r_{w g(1)}$ \\
\hline $\begin{array}{l}\text { I was able to understand the complete procedure of } \\
\text { employing the approach }\end{array}$ & 3.48 & 0.62 & 3.67 & 0.57 \\
\hline I think that the approach was easy to use & 3.38 & 0.58 & 3.83 & 0.58 \\
\hline $\begin{array}{l}\text { I think that the approach helped the team to form a } \\
\text { common understanding of the final PSS value } \\
\text { proposition }\end{array}$ & 3.71 & 0.54 & 3.97 & 0.50 \\
\hline $\begin{array}{l}\text { I think the approach helped the team identify the } \\
\text { relationships between ideas and consolidate value } \\
\text { propositions }\end{array}$ & 4.10 & 0.85 & 3.90 & 0.64 \\
\hline $\begin{array}{l}\text { I think that the approach encouraged discussion and } \\
\text { helps the team to uncover disagreements and build } \\
\text { consensus when consolidating the value propositions }\end{array}$ & 4.00 & 0.60 & 4.17 & 0.58 \\
\hline $\begin{array}{l}\text { I think the approach, based on its logic and } \\
\text { characteristics, fostered the team's motivation to } \\
\text { develop PSS value propositions }\end{array}$ & 3.90 & 0.30 & 3.97 & 0.57 \\
\hline $\begin{array}{l}\text { I think the solutions that my group proposed are } \\
\text { satisfactory }\end{array}$ & 4.00 & 0.35 & 4.10 & 0.68 \\
\hline
\end{tabular}

When comparing the gamified approach and the traditional design approach, most respondents agreed that was easy to use and to understand both approaches. Respondents partially agreed that the approaches were helpful to form a common understanding of the PSS value proposition. Most of them agreed that the approaches encouraged discussion when designing the value propositions. The degree of agreement among respondents that employed a gamified approach is higher than those using the traditional approach to identifying relationships between ideas. In contrast to the traditional approach, there was no agreement that the gamified approach had fostered the team's motivation and that the solutions developed through this approach are satisfactory. The possible reasons for this and the improvement opportunities in relation to these aspects are discussed in Section 5.

The greatest difficulties reported by the respondents, regarding the gamified approach, was the lack of time and facilitation to understand all the rules and how to apply some gaming components (mainly the benefits board and the ideation board). According to some respondents, given the time available for the design session, different rules for each round and the employment of several types of boards/cards made the gamified approach complex. It was suggested that, instead of just following the written instructions, a moderator could support the application. Respondents positively highlighted the fact that this approach helped in structuring creativity through the use of different roles and ideation cards, and in combining ideas. Some respondents stated that the separation into different rounds gave the opportunity to focus on one activity at a time, building knowledge upon the others. 
The greatest difficulty related to the traditional approach was also the timeframe to understand the activities before starting the process. Since the traditional approach allows participants greater freedom on how to perform the activities, some respondents argued that it was difficult to combine the ideas and, consequently, to define a final PSS value proposition, requiring more specific guiding rules when applying the approach. The greatest advantages reported by respondents were more related to the overall process that was also employed through the gamified approach.

For both settings, some respondents stated that the approaches inspired them when generating ideas, encouraged discussion and the evaluation of ideas based on the clarification of benefits and sacrifices. In general, the participants stated that discussions about the benefits to be promoted by the PSS value proposition and the use of PSS design options cards were the most valuable elements of the approaches. Benefits were employed to support the initial ideation and to evaluate the ideas generated. According to respondents, PSS design options significantly helped at fostering new ideas or improving ideas already proposed, since they helped broaden the solution space.

\section{Discussion}

The results from the experiment pointed out the complexity to apply the gaming components due to different roles, rules, and several interactive components (e.g., boards/cards), which affected the teams' motivation when applying the approach. This fact shows the importance of simplifying the process and to explore the role that a moderator could play in providing a common ground about the roles, rules, challenges, and on how to apply the gaming components in a clear and harmonized manner. Furthermore, a detailed overview of the entire process covered in the gamified approach could facilitate its understanding and applicability. More than providing cards with instructions, personal support for players seems to be needed, as the different background of the players might affect the understanding of the cards content. Combined with facilitation, simple pictures and text could make the cards more approachable for all players.

Facilitation might also encourage more collaboration, learning and motivation between players. This fact is directly related to the research hypothesis (Section 1). By analysing the statistical results, it was not possible to conclude that the gamified approach, as configured for this study, enhanced motivation of to the participants. However, the gamified approach supported discussions, leading to a good overall experience. In general, similar results were achieved for both approaches (whether considering the average and the interrater reliability coefficient). This might indicate that gamification is not effective per se and it is complex to apply this to design value propositions. The decision to use specific game elements and the understanding of them by players affect their motivation, experience and satisfaction.

Compared to the traditional approach, based on the answers from the open-ended questions, the gamified approach provided a more structured way to ideate and combine ideas. Usually, traditional approaches do not provide details on how participants should perform, suggesting self-management by them. Besides the benefit cards and the PSS design options cards (that were considered valuable in both approaches), ideation cards and different rounds were considered valuable in the gamified approach. The ideation cards supported the visualization of ideas in association with benefits, and the rounds made the process clearer and created sub goals to players. These elements should be explored in further version of the prototype of the gamified approach.

\section{Conclusion}

This study developed a prototype of a gamified approach to support the design of PSS value propositions and compared its applicability to a traditional design approach. The comparison was conducted by means of an experimental study combined with observation technique and feedback questionnaire.

Findings of this study revealed the potential importance of facilitation when proposing a gamified approach to design PSS value propositions. The characteristic of the traditional approach suggests freedom for participants who could self-manage how the activities would be performed. In turn, a higher effectiveness of the gamified approach in this context depends on the understanding of the mechanism and components applied, and a moderator could facilitate the process. As consequence, this affects the motivation, performance and satisfaction of players. In this context, the results from the 
experiment did not completely provide a clear conclusion about the hypothesis defined for this study. There was no agreement that the gamified approach proposed in this study has fostered motivation and has provided satisfactory solutions. This can be a consequence of how the approach was applied (without facilitation and with tight time constraints). At the same time, the gamified approach encouraged discussions and provided a good experience for players. Considering the presence of facilitation, different configurations of the game elements could be proposed and analysed to define the ideal configuration of the gamified approach that could completely attend the hypothesis defined by this study. It is highlighted that the gamified approach proposed in this study is a prototype and new iterations are still being conducted to improve the approach.

This study contributes to theory by providing lessons learned (described in Section 5) that can be used as opportunities to improve the gamified approach being developed with the aim of supporting the design of PSS value propositions. From a methodological perspective, the configuration of the experiment conducted through this study could be used as inspiration by researchers when configuring similar types of experiments. Regarding the practical perspective, this study developed a prototype of an approach, on the basis of gamification, to support the design of PSS value propositions.

Limitations of this study can be pointed out. The design session was conducted with Masters students, who are not yet practitioners working in a real industrial environment. Also, the experiment was conducted in an artificial setting (university environment). This limits the generalization of the results. However, in general, research experiments testing new approaches are still conducted in artificial settings, which do not invalidate the results, especially in the case of this study that focused on testing prototypes of design approaches. The quality of the final ideas was not discussed in this study, since the main focus was on the process and next step of this research should include this analysis.

Future work shall develop an improved version of the gamified approach based on the evidence of importance of facilitation and clear definition of game elements for players. Further requirements elicitation shall be performed to complement the information derived from the experiment. New tests shall also be performed, especially in real cases in the industry. From this, qualitative analysis of the final ideas and value proposition should be conducted to evaluate the efficacy of the approach.

\section{Acknowledgment}

This study was supported by São Paulo Research Foundation (FAPESP) under the processes 2017/27144-3 and 2018/13024-9. The opinions, hypotheses and conclusions or recommendations expressed in this material are of responsibility of the authors and do not necessarily reflect the views of FAPESP. The authors would like to extend sincere thanks to FAPESP, Brazilian Council for Scientific and Technological Development (CNPq) and the Higher Education Personnel Improvement Coordination (Capes) for supporting this research.

\section{References}

Åkesson, M. et al. (2016), "Value proposition test-driving for service innovation: How frontline employees innovate value propositions", Journal of Service Theory and Practice, Vol. 26 No. 3, pp. 338-362. https://doi.org/10.1108/JSTP-10-2014-0242

Baines, T.S. et al. (2017), "Servitization: Revisiting the State-of-the-art and Research Priorities", International Journal of Operations \& Production Management, Vol. 37 No. 2, pp. 256-278. https://doi.org/10.1108/ IJOPM-06-2015-0312

Baldassarre, B. et al. (2017), "Bridging sustainable business model innovation and user-driven innovation: A process for sustainable value proposition design", Journal of Cleaner Production, Vol. 147, pp. 175-186. https://doi.org/10.1016/j.jclepro.2017.01.081

Boehm, M. and Thomas, O. (2013), "Looking beyond the rim of one's teacup: A multidisciplinary literature review of Product-Service Systems in Information Systems, Business Management, and Engineering \& Design”, Journal of Cleaner Production, Vol. 51, pp. 245-260. https://doi.org/10.1016/j.jclepro.2013.01.019.

Breuer, H. and Lüdeke-Freund, F. (2014), "Normative Innovation for Sustainable Business Models in Value Networks", in The Proceedings of Conference-Innovation for Sustainable Economy and Society, pp. 1-17.

Duin, H. and Hauge, J.B. (2008), "REFQUEST: a multiplayer on-line game to support idea creation in innovation processes", in Fourth International Conference on Web Information Systems and Technologies, pp. 447-454. https://doi.org/10.5220/0001520504470454 
Echeveste, M.E., Amaral, C.S.T. and Rozenfeld, H. (2007), “A support tool for the selection of statistical techniques for industrial product development and improvement processes", in Complex Systems Concurrent Engineering Collaboration, Technology Innovation and Sustainability, Springer-Verlag London Ltd, London, pp. 240-248.

Fernandes, S.C. et al. (2018), "An initial prototype of a tool for defining value proposition in the product-service system (PSS) design”, in Proceedings of International Design Conference, pp. 281-292. https://doi.org/ 10.21278/idc.2018.0433

Geissdoerfer, M., Bocken, N.M.P. and Hultink, E.J. (2016), "Design thinking to enhance the sustainable business modelling process - A workshop based on a value mapping process", Journal of Cleaner Production, Vol. 135, pp. 1218-1232. https://doi.org/10.1016/j.jclepro.2016.07.020.

Hein, A.M., Sa, R. and Boutin, S. (2018), "A Methodology for Architecting Collaborative Product Service System of Systems", 2018 13th Annual Conference on System of Systems Engineering (SoSE), IEEE, pp. 5359. https://doi.org/10.1109/SYSOSE.2018.8428697

James, L.R., Demaree, R.G. and Wolf, G. (1984), "Estimating within-group interrater reliability with and without response bias", Journal of Applied Psychology, Vol. 69 No. 1, pp. 85-98. https://doi.org/10. 1037/0021-9010.69.1.85

Kerga, E. et al. (2014), "A serious game for introducing set-based concurrent engineering in industrial practices”, Concurrent Engineering-Research and Applications, Vol. 22 No. 4, pp. 333-346. https://doi.org/ $10.1177 / 1063293 \times 14550104$

Kleinsmann, M. et al. (2012), "Development of design collaboration Skills", Journal of Engineering Design, Vol. 23 No. 7, pp. 485-506. https://doi.org/10.1080/09544828.2011.619499

Laurischkat, K. and Viertelhausen, A. (2017), "Business Model Gaming: A Game-Based Methodology for EMobility Business Model Innovation", Procedia CIRP, Vol. 64, pp. 115-120. https://doi.org/10.1016/ j.procir.2017.03.051

Leitão, A. et al. (2013), "Roadmap for business models definition in manufacturing companies", Procedia CIRP, Vol. 7, pp. 383-388. https://doi.org/10.1016/j.procir.2013.06.003

Maglio, P.P. and Spohrer, J. (2013), "A service science perspective on business model innovation", Industrial Marketing Management, Vol. 42 No. 5, pp. 665-670. https://doi.org/10.1016/j.indmarman.2013.05.007

Martin, V. (2017), "Workshop de prototipação de board games", pp. 1-36.

Pezzotta, G. et al. (2016), "Towards a methodology to engineer industrial product-service system - Evidence from power and automation industry", CIRP Journal of Manufacturing Science and Technology, Vol. 15, pp. 19-32. https://doi.org/10.1016/j.cirpj.2016.04.006

Pogue, G.P., Bravo, M. and Tran, S. (2016), "Iteration strategies for successful positioning of innovative products into new markets", IEEE International Professional Communication Conference, IEEE, 2016Novem, pp. 1-9. https://doi.org/10.1109/IPCC.2016.7740539

Rau, C., Zbiek, A. and Jonas, J. (2017), "Creating Competitive Advantage from Services Creating Competitive Advantage from Services A Design Thinking Case Study from the Commodities Industry", ResearchTechnology Management, Vol. 60 No. 3, pp. 48-56. https://doi.org/10.1080/08956308.2017.1301003

Reigado, C.R. et al. (2017), "A Circular Economy Toolkit as an Alternative to Improve the Application of PSS Methodologies”, Procedia CIRP, pp. 37-42. https://doi.org/10.1016/j.procir.2017.03.034

Resta, B. et al. (2017), "Enhancing the Design and Management of the Product-Service System Supply Chain: An Application to the Automotive Sector", Service Science, Vol. 9 No. 4, pp. 302-314. https://doi.org/ 10.1287/serv.2017.0193

Rozenfeld, H., Rosa, M. and Fernandes, S.C. (2018), "Servitization methodology: PSS design, change management or business model innovation?", In: Schützer, K. (Ed.), Proceedings of the 23rd International Seminar on High Technology, UNIMEP, Piracicaba, pp. 91-116.

Schell, J. (2015), The Art of Game Design, 2nd ed, CRC Press, Pittsburgh.

Symon, G. (2004), "Qualitative Research Diaries", in Essential Guide to Qualitative Methods in Organizational Research. 1st edn. Sage Publications, Inc., London, p. 409.

Voss, C., Tsikriktsis, N. and Frohlich, M. (2002), "Case research in operations management", International Journal of Operations \& Production Management, Vol. 22 No. 2, pp. 195-219. https://doi.org/10.1108/ 01443570210414329

Werbach, K. and Hunter, D. (2012), How game thinking can revolutionize your business, Gamification of Learning. Wharton Digital Press. Available at: https://www.lynda.com/Higher-Education-tutorials/Gamethinking/173211/197007-4.html 